\title{
Reactive Spark Plasma Sintering: Successes and Challenges of Nanomaterial Synthesis
}

\author{
Dina V. Dudina ${ }^{1}$ and Amiya K. Mukherjee ${ }^{2}$ \\ ${ }^{1}$ Institute of Solid State Chemistry and Mechanochemistry SB RAS, Kutateladze Street 18, Novosibirsk 630128, Russia \\ ${ }^{2}$ Department of Chemical Engineering and Materials Science, University of California, Davis, 1 Shields Avenue, Davis, CA 95616, USA
}

Correspondence should be addressed to Dina V. Dudina; dina1807@gmail.com

Received 21 February 2013; Accepted 4 June 2013

Academic Editor: Izabel Fernanda Machado

Copyright (c) 2013 D. V. Dudina and A. K. Mukherjee. This is an open access article distributed under the Creative Commons Attribution License, which permits unrestricted use, distribution, and reproduction in any medium, provided the original work is properly cited.

\begin{abstract}
Spark plasma sintering (SPS), initially developed as an advanced sintering technique for consolidating nanopowders into nanostructured bulk materials, has been recently looked at in much broader perspective and gained a strong reputation of a versatile method of solid state processing of metals, ceramics, and composites. The powders in the SPS-dies experience the action of pulsed electric current and uniaxial pressure; they are heated at very high rates unachievable in furnace heating and sintered within shorter times and at lower temperatures than in conventional methods. The principle of SPS and convenient design of the facilities make it attractive for conducting solid state synthesis. In this paper, based on our own results and the literature data, we analyze the microstructure formation of the products of chemical reactions occurring in the SPS in an attempt to formulate the requirements to the microstructure parameters of reactant mixtures and SPS conditions that should be fulfilled in order to produce a nanostructured material. We present successful syntheses of nanostructured ceramics and metal matrix composite with nanosized reinforcements in terms of microstructure stability and attractive properties of the materials and discuss the challenges of making a dense nanostructured material when reaction and densification do not coincide during the SPS. In the final part of the paper, we provide an outlook on the further uses of reactive SPS in the synthesis of nanostructured materials.
\end{abstract}

\section{Introduction}

Spark plasma sintering (SPS) has attracted enormous interest from researchers and engineers in the past two decades such that it is now difficult to imagine the development of modern materials science without the advantages offered by this method. SPS uses a combination of uniaxial pressure and pulsed direct current to heat and sinter the powder specimen placed in a die usually made of graphite [1]. When the powders pressed in a die are conductive, the current passes directly through the sample and heats the material rapidly. Nonconductive materials are usually heated by means of heat conduction from the die walls. The role of the ON-OFF pulsing is to create hot spots at the interparticle contacts constantly moving within the sample during the sintering cycle. The sintering is performed in dynamic vacuum protecting sensitive materials from oxidation, in the meantime enabling processes of chemical reduction. The main advantage of the SPS over conventional pressure-less furnace sintering and hot pressing is a possibility of shortening densification time, lowering sintering temperature and producing nearly fully dense or fully dense materials with limited grain growth. High activity in the SPS-related research in different laboratories is demonstrated by reviews and research articles discussing the process features and mechanisms [2-8], sintering possibilities of nanograined materials [9-11], and systematically describing the material systems [11-13] processed by this method.

With SPS advancing as a promising method for rapid and successful consolidation of nanopowders and nanostructured materials, it has been soon recognized that chemical reactions can be also performed in the SPS so that synthesis and 
densification could be combined saving processing time and adding flexibility to the materials design. Researchers became intrigued by a possibility of making nanostructured materials by chemical reactions conveniently placing solid reactants in a SPS-die and subjecting them to pulsed current. If the reactants are prepared in such a way that the reaction occurs at multiple points within the reactant mixture, the treatment of the mixture by pulsed current is highly suitable for reaction initiation and ultimately for synthesizing a nanograined product. Then, if SPS can preserve the microstructure of the ex situ synthesized nanopowders, it is likely that the nanostructured product obtained in situ could be consolidated into a nanostructured body.

By now, reactive SPS has been used for synthesizing nanomaterials and making nanocomposites in a large number of systems. In this paper, we analyze the successes and challenges of reactive SPS and provide an outlook on the further developments in this area. We did not aim at making a list of all studies that have been published up to date, rather, by analyzing the literature data and our own results, we have tried to reveal the factors responsible for the successes of reactive SPS in nanomaterial synthesis and issues pertaining to the processing that still remain unsolved. As in other reactive sintering processes, when new phases form during the SPS, such factors as uniformity of distribution of the reactants in the mixture, heat release during exothermic reactions, specific volume change and the presence of reaction byproducts need to be taken into account when the microstructure evolution of the synthesized product is traced. In addition to factors common to all reactive processes, there are specific features of the microstructure development during the reactive SPS, which are related to the use of electric current: the changes in electrical conductivity of the material during the course of reaction and the presence of hightemperature regions at the inter-particle contacts serving as reaction initiation zones.

\section{SPS-Dies as Chemical Reactors: Targeted Synthesis and Undesirable Chemical Reactions}

Sintering dies of the SPS facilities can be considered as hightemperature reactors with a controlled atmosphere. Figure 1 shows a schematic of the die-punch setup normally used in the SPS experiments. Beneficially for oxidation-sensitive materials, dynamic vacuum of the SPS chamber creates a protective environment. In the presence of carbon as a material of the die/punches and foil lining the walls of the die (a possible option), the atmosphere of the chamber becomes reducing, which can be helpful in full chemical reduction of oxides present in the material in small concentrations as additives or contamination, or lead to partial reduction of the oxide material being sintered. The reducing environment of the SPS is favorable for conducting reduction reactions to form new phases and nanocomposite structures (e.g., $\mathrm{Ni}$ nanoparticle-toughened alumina in situ formed from coprecipitated $\mathrm{Al}_{2} \mathrm{O}_{3}$ and $\mathrm{NiO}$ oxides [14, 15]; magnetic $\mathrm{FePt} / \mathrm{Fe}_{3} \mathrm{Pt}$ nanocomposites, in which the $\mathrm{Fe}_{3} \mathrm{Pt}$ phase is

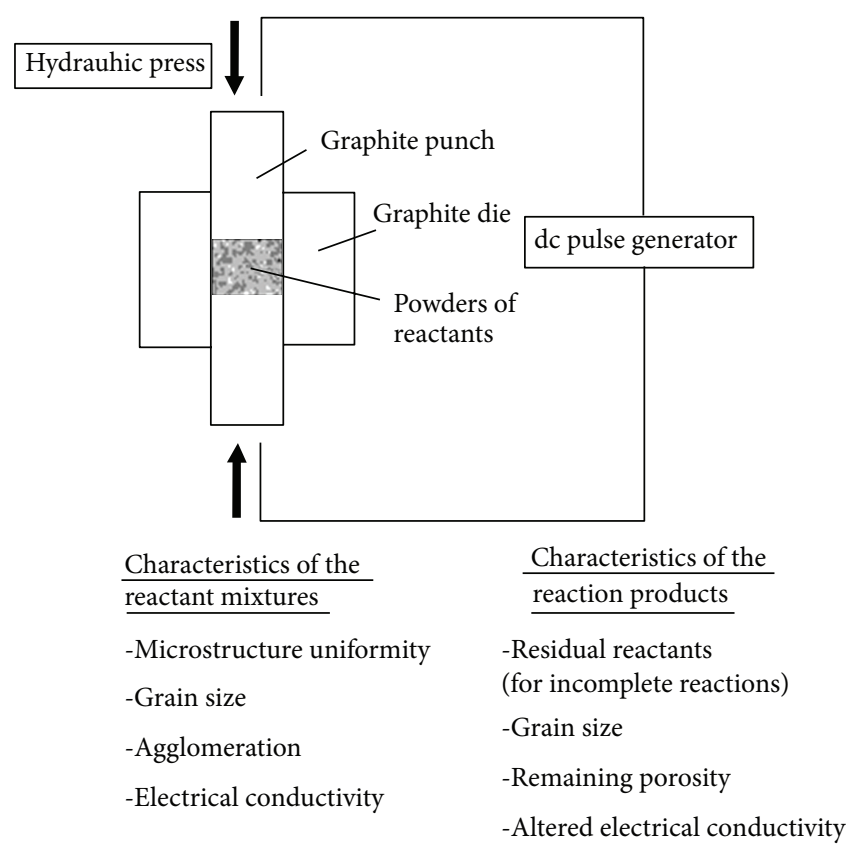

FIGURE 1: A die-punch setup of the SPS facility as a chemical reactor.

formed as a result of in situ reduction of $\mathrm{Fe}_{3} \mathrm{O}_{4}$ during the SPS [16]) and to tailor the phase composition and microstructure of the surface of SPS-ed specimens (e.g., Fe-FeAl $\mathrm{O}_{4}-\mathrm{Al}_{2} \mathrm{O}_{3}$ composites, in which the $\mathrm{Fe}$ phase in the surface layer is formed in situ by reduction [17]). The reducing action of the SPS environment can be enhanced by increasing the SPS temperature: the higher the SPS-temperature, the lower oxygen content will be retained in the SPS-ed materials.

Thanks to the capabilities of the SPS facilities, such features of reactive sintering as specific volume changes and heat release during exothermic reactions, which create complications in conventional sintering process, can be addressed. Applied pressure helps consolidate the porous reaction product into a denser material upon reaction completion. During the SPS-process, a controlled power input balances the heat from an exothermic reaction so that a temperature schedule is maintained with only small deviations of the measured temperatures from the programmed values. This is achieved by a controlled drop of current through the sample once the reaction is initiated in the system. Experimentally, a stability of the programmed temperature schedule has been proved during the synthesis of titanium diboride [18] and rhenium diboride [19] from elements in the SPS. Compounds that form with extensive evolution of heat can be synthesized in the presence of a diluent, which is introduced into the reactant mixture to decrease the adiabatic temperature of the reaction and to control the grain size of in situ synthesized phases. Similar to conventional selfpropagating high-temperature synthesis, the reaction mode in reactive SPS depends on the heating rate with a certain minimum heating rate required to ignite the reaction and to carry it out in a self-sustaining or thermal explosion mode.

Pulsed direct current can enhance the reaction kinetics when the reactants are brought to interaction in the SPS. 
This effect is, however, system-dependent. Applied currents induce faster growth of the $\mathrm{MoSi}_{2}$ product layer in the Mo$\mathrm{Si}$ system [4] relative to the reaction performed without current. In the Hf-B system, no reactivity changes have been observed under applied current as the thicknesses of the $\mathrm{HfB}_{2}$ product layers formed during the SPS agreed well with the calculations for diffusion couples [20].

The chemical properties and microstructural characteristics of the reactant mixture such as mixing uniformity, grain size and degree of agglomeration will influence the microstructure of the as synthesized product obtained by the SPS. This statement will be also true for other processes of reactive sintering. Specific to the synthesis in the SPS is a change in the electrical conductivity of the materials in the die with reaction advancement and a possibility of controlling the synthesis by varying the electrical conductivity of the reactants. If a high-conductivity additive is introduced into an insulating mixture of the reactants, local high-temperature spots will form within the sample in the regions adjacent to the conducting particles; it is in these hot spots that the reaction will start. When pulsed electric current passes through Ti-B powder mixtures containing $\mathrm{Mg}$ additions, hot spots form in the areas adjacent to the $\mathrm{Mg}$ grains as the electrical conductivity of $\mathrm{Mg}$ is higher than that of the Ti$\mathrm{B}$ mixture [18]. The observed effects of the $\mathrm{Mg}$ additions are a reduced ignition temperature and a more uniform sintered product. A similar approach was used for initiating decomposition of magnesium hydride $\mathrm{MgH}_{2}$, which is an insulator [21]. In order to increase electrical conductivity, graphite was added to the $\mathrm{MgH}_{2}$ powder. Magnesium, the product of decomposition, increases the electrical conductivity of the material in the SPS-die. This example shows that as the reaction product accumulates, the conductivity of the material in the sintering die changes; if it increases, the reaction is self-accelerated due to the presence of in situ formed conductive particles inducing the formation of hot spots in the remaining, not yet fully reacted, mixture.

Partial reduction of oxides during the SPS presents another way of increasing electrical conductivity of the material in the sintering die. Interestingly enough, it can be used to advantage to facilitate densification of materials that would otherwise have been heated through conduction from the die only [23]. During the SPS of nanocrystalline rutile $\mathrm{TiO}_{2}$, its partial reduction led to the formation of oxygen vacancies and an increase in its electrical conductivity, which, in turn, made it possible for the current to pass through the sample ultimately resulting in successful densification of the material at unexpectedly low temperatures and pressures.

An important factor in the SPS synthesis is the temperature range of the reaction. If the reaction does occur within a wide temperature range during the SPS heating, the upper temperatures of the range are likely to destroy the nanostructure of the synthesized product formed at the initial heating stages. These considerations are illustrated by the synthesis of $\mathrm{AlMgB}_{14}$ in the SPS in a mechanically milled mixture of $\mathrm{Al}, \mathrm{Mg}$, and $\mathrm{B}$ [24]. The first boride phase formed was the lower boride $\mathrm{AlMgB}_{4}$, which appeared in the sintered sample at $600^{\circ} \mathrm{C}$. The $\mathrm{AlMgB}_{14}$ phase was found after the
SPS at $800^{\circ} \mathrm{C}$ and the synthesis continued until the reaction was complete at $1325^{\circ} \mathrm{C}$. The noticeable shrinkage of the sample was observed starting from $1250^{\circ} \mathrm{C}$, which is much higher than the reaction onset temperature. Obviously, a finegrained product was not favored as the grains nucleated in the beginning of the process coalesced and continued to grow with increasing SPS temperature.

Chemical changes in materials during the SPS can be due to reactions that are purposefully conducted (targeted synthesis of new phases) or to undesirable chemical reactions. The latter are interfacial reactions between the phases that are to be preserved, or reduction of oxides that lose their valuable properties upon change in the oxygen content in the SPS environment. An example of an interfacial reaction occurring mainly in the vicinity of contacts between the powder particles was observed in titanium silicon carbide $\mathrm{Ti}_{3} \mathrm{SiC}_{2}$ reinforced copper composites ex situ synthesized and SPSed [25]. During sintering of $5 \mathrm{vol} . \% \mathrm{Ti}_{3} \mathrm{SiC}_{2}-\mathrm{Cu}$ powders, the low intrinsic resistivity of the composite particles and a wellestablished contact between the powder agglomerates due to applied pressure helped avoiding melting of the copper matrix, which would otherwise have taken place as a result of a local increase in temperature at the particle contacts under pulsed electric current. In the 18 vol.\% $\mathrm{Ti}_{3} \mathrm{SiC}_{2}-\mathrm{Cu}$ composite, which has a higher intrinsic resistivity and whose higher hardness prevents the formation of an intimate contact between the composite particles under the chosen pressure (40 MPa), SPS resulted in partial melting of the $\mathrm{Cu}$ matrix.

The evidence of melting and resolidification can be seen in the images taken both from the polished cross section and fracture surface of the composite (Figures 2(a) and 2(b)). The XRD phase analysis (Figure 2(c)) shows that local melting of $\mathrm{Cu}$ resulted in its fast interaction with $\mathrm{Ti}_{3} \mathrm{SiC}_{2}$ leading to the formation of $\mathrm{TiC}_{x}$ separated from the $\mathrm{Cu}-\mathrm{Si}$ melt during the SPS. The EDS analysis confirmed the absence of $\mathrm{Ti}$ and the presence of $\mathrm{Cu}$ and $\mathrm{Si}$ in the resolidified areas marked in Figure 2(a). The concentration of $\mathrm{Si}$ in such areas was determined to be $11 \%$ by the EDS, which corresponds to the maximum solubility of silicon in copper. This result demonstrated that local melting during the SPS can destabilize the $\mathrm{Ti}_{3} \mathrm{SiC}_{2}$ phase leading to deintercalation of $\mathrm{Si}$, which dissolves in $\mathrm{Cu}$. Fast cooling of inter-particle contacts during the SPS enables supersaturated $\mathrm{Cu}$ (Si) solid solutions to form. Partial melting of the $\mathrm{Cu}$ matrix compromises phase stability and uniformity of the microstructure of the $\mathrm{Ti}_{3} \mathrm{SiC}_{2}-\mathrm{Cu}$ composites and therefore, cannot be suggested as a pathway to enhanced densification.

Partial reduction of oxides in the SPS environment can lead to the formation of oxygen vacancies in their crystalline structure $[22,26]$. Jiang and Mukherjee have sintered solgel-produced $\mathrm{Y}_{2} \mathrm{O}_{3}-\mathrm{MgO}$ composite nanopowders and produced a nanograined compact [22]. Due to oxygen losses, the crystalline lattices of both phases experienced contraction as indicated by decreased lattice parameters determined from the shift of the positions of the corresponding peaks on the XRD patterns (Figure 3). Low infrared transmission of the SPS-ed $\mathrm{Y}_{2} \mathrm{O}_{3}-\mathrm{MgO}$ nanocomposite could be greatly improved when the oxygen content was restored by annealing in air after the SPS (Figure 4). 


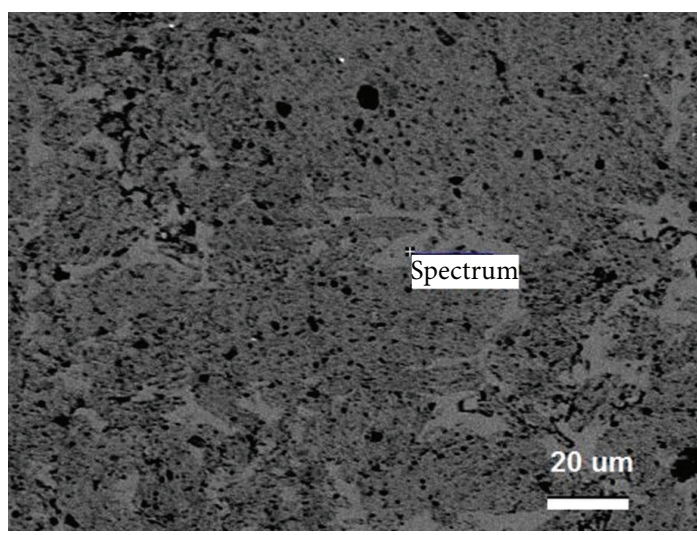

(a)

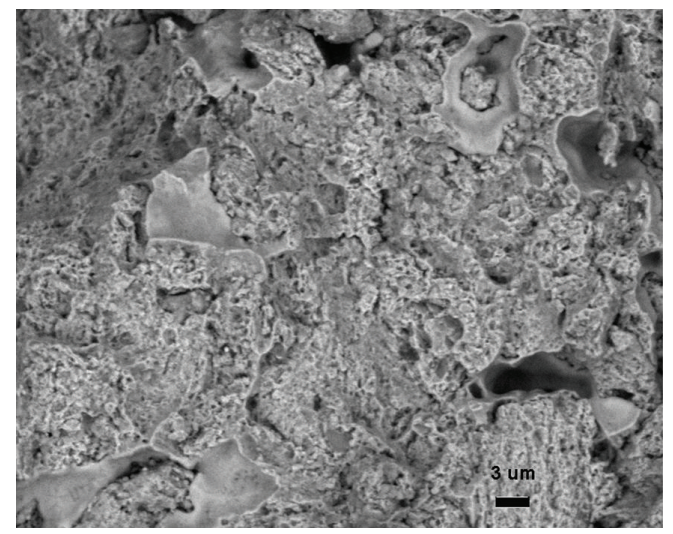

(b)

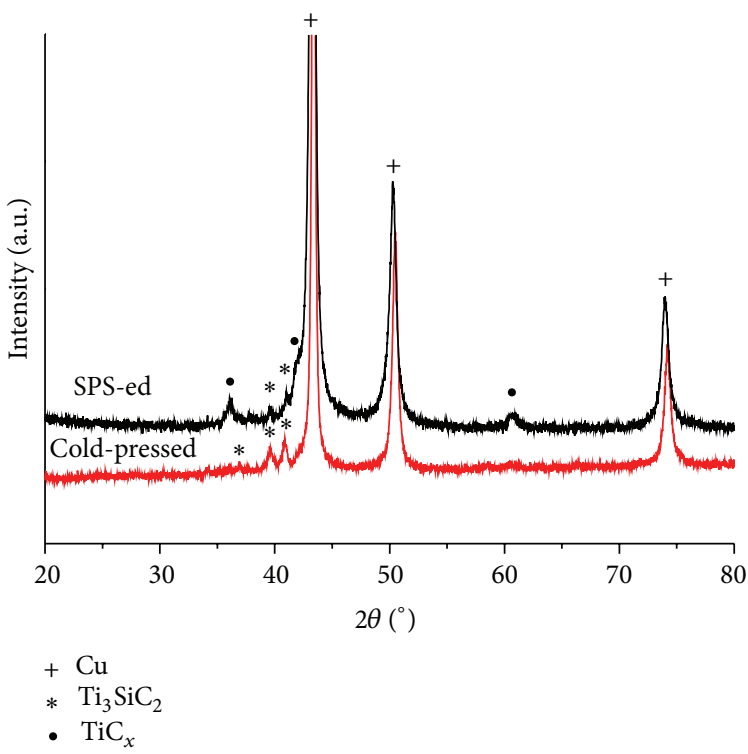

(c)

FIgURE 2: Microstructure of the SPS-ed 18 vol.\% $\mathrm{Ti}_{3} \mathrm{SiC}_{2}-\mathrm{Cu}$ composite ((a)-polished cross section and (b) - fracture surface) and XRD patterns of the cold-pressed and SPS-ed 18 vol. $\% \mathrm{Ti}_{3} \mathrm{SiC}_{2}-\mathrm{Cu}$ compacts (c).

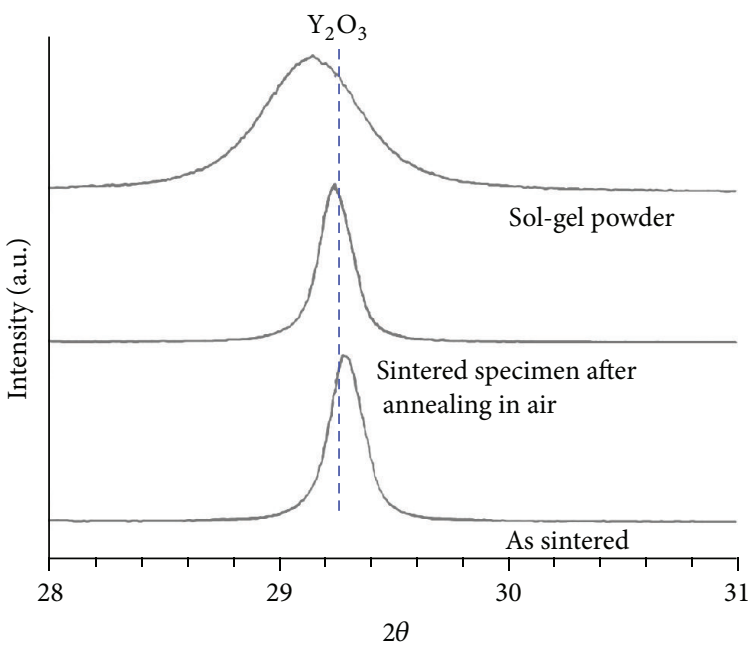

(a)

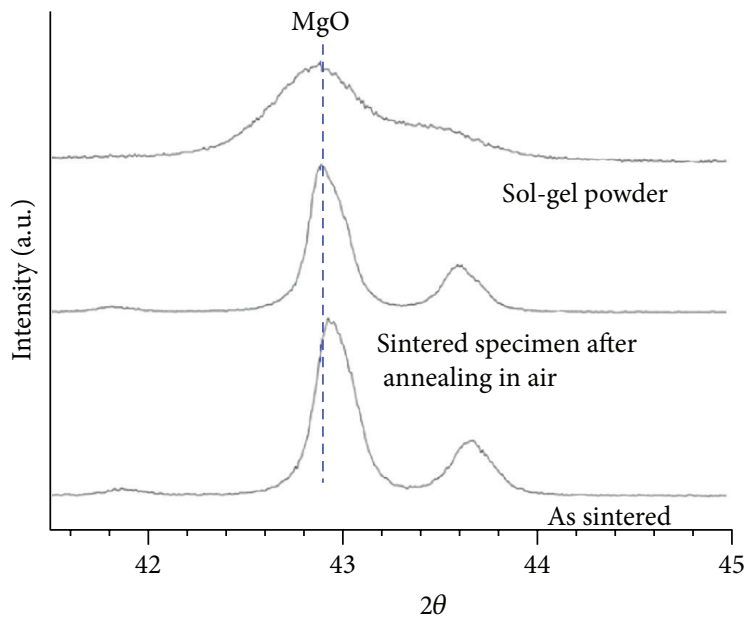

(b)

FIGURE 3: XRD patterns of the $\mathrm{Y}_{2} \mathrm{O}_{3}-\mathrm{MgO}$ nanocomposites: powders, SPS-ed and annealed in air after the SPS, showing the shift of the peak positions of both oxides (reprinted from [22], Copyright (2011), with permission from Elsevier). 


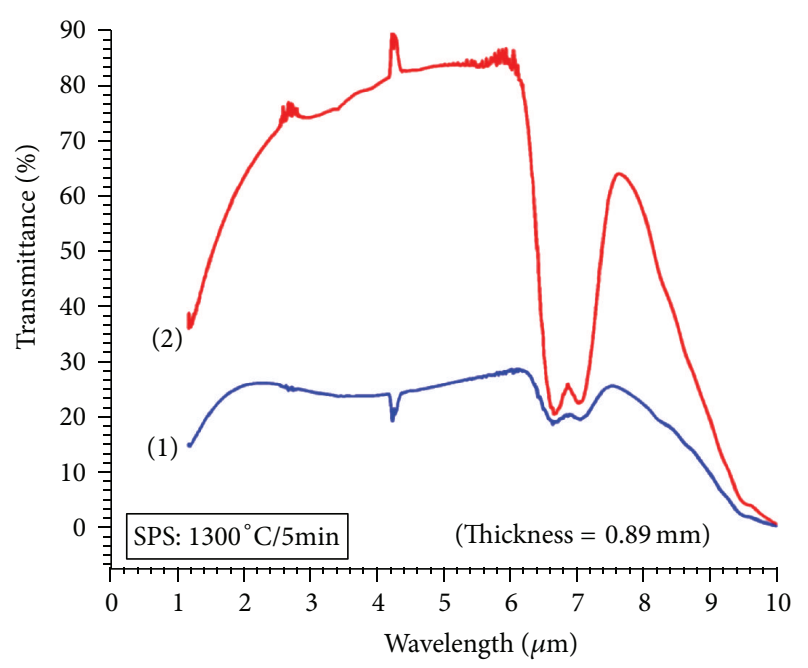

FIgure 4: Transmission spectra of SPS-ed $\mathrm{Y}_{2} \mathrm{O}_{3}-\mathrm{MgO}$ nanocomposite (1) and after annealing in air (2) (reprinted from [22], Copyright (2011), with permission from Elsevier).

\section{Successful Syntheses of Nanostructured Materials and Nanocomposites by Reactive SPS}

In order to obtain a nanograined or nanocomposite product by a chemical reaction in the SPS, careful choice of the reactants and their preparation procedures should be made. The microstructure of the precursor is of primary importance. In order to initiate the reaction at many nucleation sites at the same time, a large number of contact points between the solid reactants should be established, which is favored by well-developed interfaces in the reactant mixture. The most visible solution along this line is to have particles of reactants as small as possible and to mix them thoroughly avoiding the formation of aggregates of particles of the same type. However, as will be discussed later, a mixture of fine particles or grains is not the only way to create conditions for the formation of nanosized reaction products.

If two nanopowders are selected as initial reactants and the aggregates of each component are retained in the mixture, then the availability of the reactants to each other is greatly reduced. In such cases, sintering of particles of the same powder can occur before the reaction starts. Kim et al. [27] applied dry mixing and ultrasonic treatment in liquid in an attempt to improve the mixing uniformity of nickel and aluminum nanopowders and proved the former to be more efficient in breaking the nanoparticle aggregates. In order to obtain a nanograined product, it may be sufficient to have only one reactant in the form of nanopowder. A demonstration of this possibility is the synthesis of nano- $\mathrm{HfB}_{2}$ through the reaction between micron-sized $\mathrm{B}_{4} \mathrm{C}$ powder, $\mathrm{HfO}_{2}$ nanopowder, and phenolic resin [28]. The crucial influence of the preparation procedure of a two-phase mixture of nanopowders on the reaction onset temperature and resultant microstructure of the reaction product was clearly shown in a comparative study by Stanciu et al. [29], who used three types of precursors for reactive sintering of $\mathrm{Al}_{2} \mathrm{TiO}_{5}$ : co-gelified $\mathrm{Al}_{2} \mathrm{O}_{3}$ and
$\mathrm{TiO}_{2}$ powders, mechanical mixtures of $\mathrm{Al}_{2} \mathrm{O}_{3}$ and $\mathrm{TiO}_{2}$ individual sol-gel powders, and powders synthesized by coprecipitation. As is seen from the XRD patterns, the reaction between co-gelified $\mathrm{Al}_{2} \mathrm{O}_{3}$ and $\mathrm{TiO}_{2}$ powders was complete after the SPS at $1100^{\circ} \mathrm{C}$ occurring only partially in the other two precursors (Figure 5).

A more widely used powder preparation technique for the subsequent reactive SPS is mechanical milling [32], in which powders with a size from several to several tens of microns are normally used as raw materials. The powder mixtures are placed in a vial and subjected to impact and shear from the milling media. During milling, the powders experience grinding and particle and grain size reduction and accumulate defects of the crystalline structure. Repeated fracturing and cold welding of the particles during mechanical milling gradually refine the microstructure of the milled mixture, improve its uniformity and increase the interfacial area between the components. If high-intensity milling is used, the targeted reaction can partially occur during milling. The presence of certain amounts of reaction products in the mixture prior to sintering can help form and preserve a nanostructured material after the SPS when the product grains serve as multiple nucleation centers. As was shown by Munir [9], the presence of reaction products in the mechanically milled Mo-Si mixture helped achieve a finergrained product synthesized in the SPS. However, depending on the mixing uniformity, distribution and number/size of the product grains formed during milling, an opposite influence can be also expected if a few product grains formed during milling continue to grow consuming the reactants during the SPS. In such cases, a coarse-grained material will develop as a result of the reactive SPS.

Sintering of powder precursors with well-developed interfaces between the reactants is the most common approach to the synthesis of nanomaterials by reactive SPS. Interestingly enough, interfaces can develop during the reaction itself, if the latter proceeds through several stages and thus has a complex mechanism. Zhang et al. [30] have shown that a phase with grains as small as $100 \mathrm{~nm}$ can form as a result of a solid state reaction between micron-sized powders. They have synthesized a $\mathrm{Ti}_{3} \mathrm{SiC}_{2}-\mathrm{SiC}$ composite from the mixture of Ti, $\mathrm{C}$ and $\mathrm{Si}$. The intermediate crystalline phases $\mathrm{TiC}_{x}$ and $\mathrm{Ti}_{5} \mathrm{Si}_{3} \mathrm{C}_{y}$ formed first from the elements and then participated in the reaction:

$$
\begin{aligned}
& \left(\frac{4}{3}-3 z\right) \mathrm{TiC}_{x}+\frac{1}{3} \mathrm{Ti}_{5} \mathrm{Si}_{3} \mathrm{C}_{y} \\
& +\left(2-\frac{4}{3 x}-(1-3 x) z-\frac{1}{3 y}\right) \mathrm{C} \\
& \longrightarrow(1-z) \mathrm{Ti}_{3} \mathrm{SiC}_{2}+z \mathrm{SiC} .
\end{aligned}
$$

The resultant $\mathrm{SiC}$ phase had a grain size of about $100 \mathrm{~nm}$, while the $\mathrm{Ti}_{3} \mathrm{SiC}_{2}$ phase had grains grown up to $5 \mu \mathrm{m}$ (Figure 6). The formation of $\mathrm{SiC}$ through intermediate products rather than by a direct reaction from the elements appears to be crucial for the microstructure development of the $\mathrm{Ti}_{3} \mathrm{SiC}_{2}-\mathrm{SiC}$ nanocomposites, the mixture of intermediate phases possessing a refined structure relative to that of the 


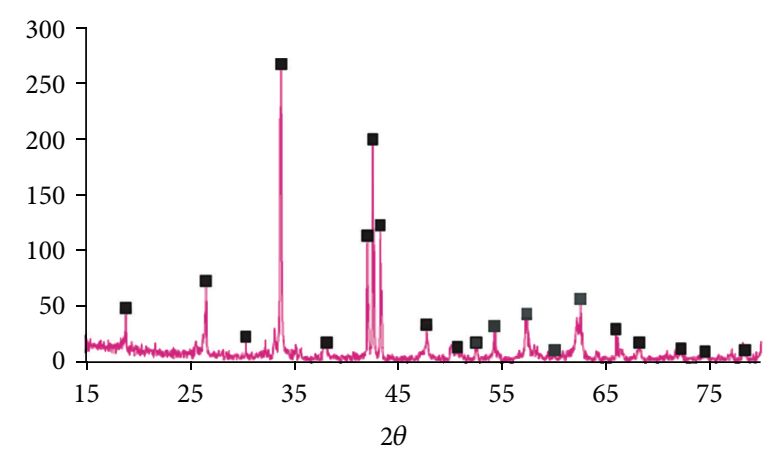

(a)

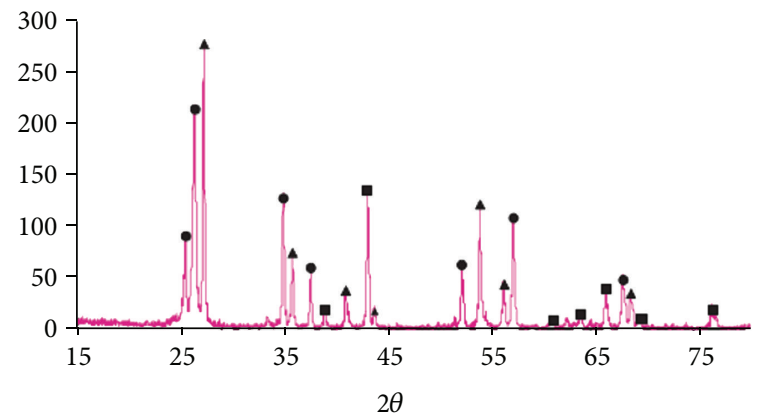

(b)

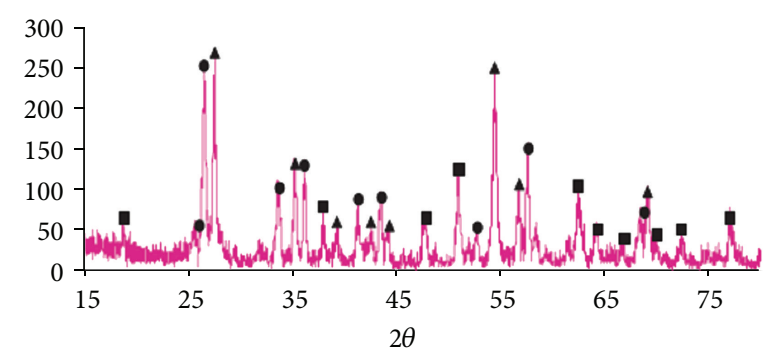

(c)

FIGURE 5: XRD patterns of the SPS-ed compacts produced from $\mathrm{Al}_{2} \mathrm{O}_{3}$ and $\mathrm{TiO}_{2}$ nanopowder mixtures of different processing histories, SPS-temperature $1100^{\circ} \mathrm{C}$ : (a)-co-gelified $\mathrm{Al}_{2} \mathrm{O}_{3}$ and $\mathrm{TiO}_{2}$ powders, (b)-mechanical mixtures of $\mathrm{Al}_{2} \mathrm{O}_{3}$ and TiO ${ }_{2}$ individual sol-gel powders, (c) - powders synthesized by co-precipitation; squares- $\mathrm{Al}_{2} \mathrm{TiO}_{5}$, triangles- $\mathrm{TiO}_{2}$, and circles- $\mathrm{Al}_{2} \mathrm{O}_{3}$ (reprinted from [29], Copyright (2004), with permission from Elsevier).

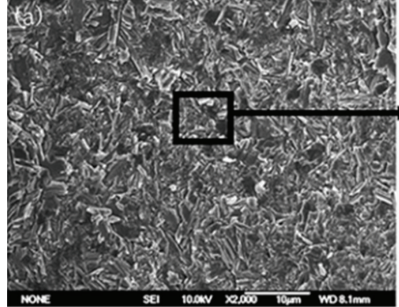

(a)

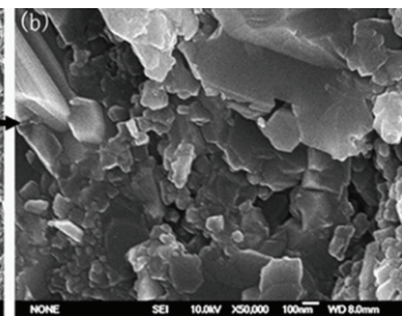

(b)
FIgure 6: Fracture surface of $\mathrm{Ti}_{3} \mathrm{SiC}_{2}-\mathrm{SiC}$ nanocomposite SPSed at $1280^{\circ} \mathrm{C}$ showing grains of $\mathrm{SiC}$ about $100 \mathrm{~nm}$ in size, (a) lower magnification, (b)-higher magnification (reprinted from [30], Copyright (2007), with permission from Elsevier).

reactant mixture. Similar observations have been reported by Wang et al. [33] for the submicron-grained $\mathrm{TiN}-\mathrm{Al}_{2} \mathrm{O}_{3}$ composites formed from $\mathrm{AlN}, \mathrm{TiO}_{2}$ and $\mathrm{Ti}$ powders, all three having particles from several to several tens of microns. Though the powders were mixed by milling, the conditions of mixing were mild (mixing was conducted in ethanol); therefore, a significant grain size reduction could not be expected. From the reported experimental results, it can be assumed that the fine-grained structure of the composite was due to a sequence of several solid state reactions occurring in the reactant mixture.

Flexible control over the SPS parameters allows inducing nanocrystallization of amorphous metallic $[34,35]$ and nonmetallic [36] matrices and maintaining the nanostructure of the composite materials until the end of sintering. A further

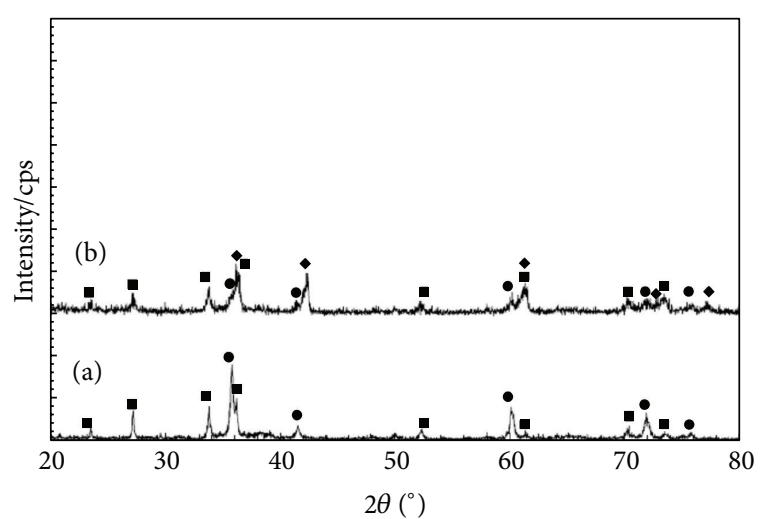

$$
\begin{aligned}
& \text { - } \beta-\mathrm{Si}_{3} \mathrm{~N}_{4} \\
& \text { - } \mathrm{SiC} \\
& \text { - } \mathrm{TiC}_{0.3} \mathrm{~N}_{0.7}
\end{aligned}
$$

FIGURE 7: XRD patterns of the $\mathrm{Si}_{3} \mathrm{~N}_{4}$-SiC ceramic nanocomposite obtained by SPS of a Si-C-N amorphous precursor (a) and $\mathrm{Si}_{3} \mathrm{~N}_{4}$ $\mathrm{SiC}-\mathrm{TiC}_{0.3} \mathrm{~N}_{0.7}$ ceramic nanocomposite obtained by reactive SPS in a mixture of nanocrystalline $\mathrm{TiO}_{2}$ with amorphous $\mathrm{Si}-\mathrm{C}-\mathrm{N}$ (reprinted from [31], Copyright (2004), with permission from Elsevier).

development of this processing route is the use of amorphous solids as reactants in mixtures with other phases. Following this line, Duan et al. [31,37] synthesized $\mathrm{Si}_{3} \mathrm{~N}_{4}-\mathrm{SiC}-\mathrm{TiC}_{0.3} \mathrm{~N}_{0.7}$ ceramic nanocomposites (Figure 7) by reactive SPS starting from a mixture of nanocrystalline $\mathrm{TiO}_{2}$ and an amorphous $\mathrm{Si}-\mathrm{C}-\mathrm{N}$ material obtained by pyrolysis of a polymer. In the synthesized composite, the $\mathrm{TiC}_{0.3} \mathrm{~N}_{0.7}$ phase formed 


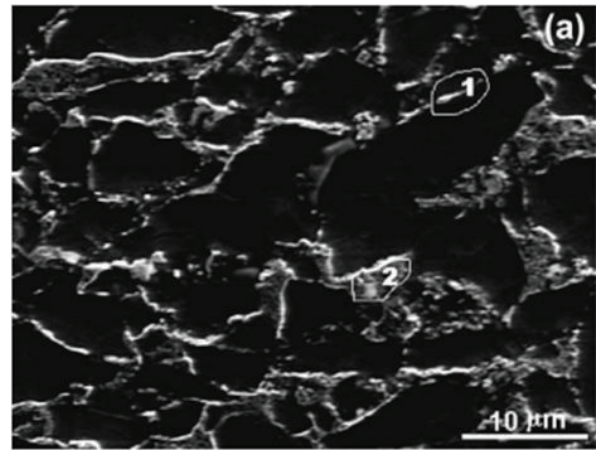

(a)

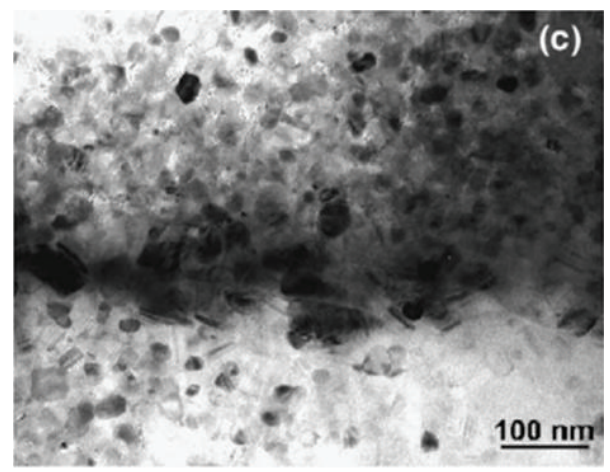

(c)

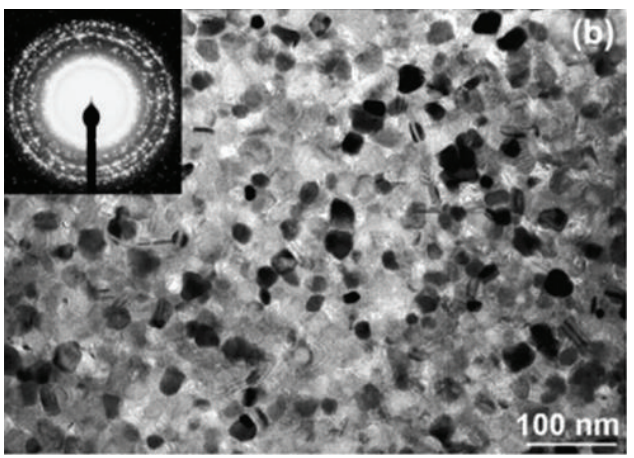

(b)

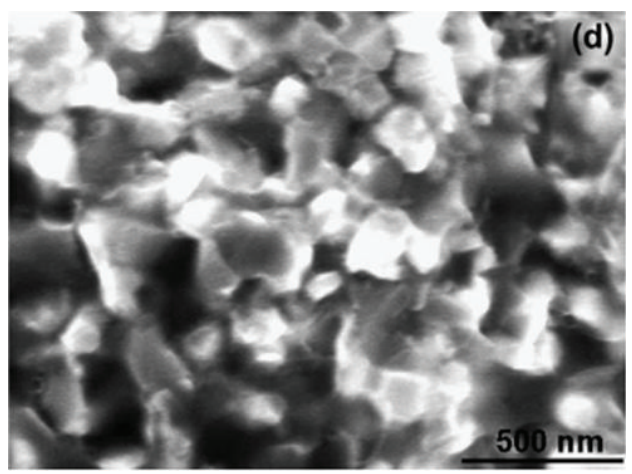

(d)

Figure 8: $\mathrm{Si}_{3} \mathrm{~N}_{4} / \mathrm{SiC} / \mathrm{TiC}_{0.3} \mathrm{~N}_{0.7}$ nanocomposite: (a) - fracture surface, SEM; (b) - microstructure of dark areas in (a) corresponding to the $\mathrm{Si}_{3} \mathrm{~N}_{4} / \mathrm{SiC}$, TEM; (c) - region 1 in (a), TEM; (d) - region 2 in (a) corresponding to the $\mathrm{TiC}_{0.3} \mathrm{~N}_{0.7}$ phase, SEM (reprinted from [31], Copyright (2004), with permission from Elsevier).

a network composed of 100-300 nm grains, which penetrated through the regions of the $\mathrm{Si}_{3} \mathrm{~N}_{4} / \mathrm{SiC}$ composite with grains ranging from 20 to $30 \mathrm{~nm}$ (Figure 8 ); improved densification of the three-phase composite was achieved in comparison to the SPS of the amorphous Si-C-N alone.

If refractory compounds are synthesized in the SPS form by exothermic chemical reactions, local heat evolution in the reaction initiation zones and the concomitant temperature rise in the adjacent regions can make it very challenging to synthesize materials with nanosized grains. If the reaction is moderately exothermic, the product grains do not grow as fast and, provided a suitable SPS schedule is found for densification, a nanostructured bulk product can be obtained. Examples of successful syntheses have been reported by Munir [9], who synthesized nanostructured $\mathrm{MoSi}_{2}$ with $140 \mathrm{~nm}$ grains, and by Paris et. al. [38], who showed that iron aluminides with $30-90 \mathrm{~nm}$ grains could be obtained from mechanically milled mixtures, in which the reactants were refined and thoroughly intermixed at the nanoscale.

Ceramic nanomaterials and nanocomposites synthesized in the SPS show attractive mechanical properties making a careful selection of reactants and process parameters worthwhile. One of the most significant achievements of the reactive SPS is the preparation of fracture-tough ceramics. Monolithic titanium monoboride $\mathrm{TiB}$ with needle-shaped grains produced by reactive SPS possessed a fracture toughness of $5.9 \pm 0.4 \mathrm{MPa} \cdot \mathrm{m}^{1 / 2}$ [39]. A fracture toughness of
6.5 MPa $\cdot \mathrm{m}^{1 / 2}$ and a microhardness of $20.6 \mathrm{GPa}$ were achieved in $\mathrm{TiN}^{-\mathrm{TiB}_{2}}$ in situ composites [40]. Along with high fracture toughness, other attractive properties appeared: $\mathrm{Si}_{3} \mathrm{~N}_{4}-\mathrm{SiC}$ $\mathrm{TiC}_{0.3} \mathrm{~N}_{0.7}$ nanocomposite showed a fracture toughness of $6.7 \mathrm{MPa} \cdot \mathrm{m}^{1 / 2}$ and metal-like electrical conductivity $[31,37]$ while nanoorganized $\mathrm{MoSi}_{2}$ synthesized in the SPS exhibited a fracture toughness of $5.8 \pm 0.4 \mathrm{MPa} \cdot \mathrm{m}^{1 / 2}$ and better oxidation resistance than its microcrystalline analog [41].

Full reduction of a metal oxide to a metallic phase in the SPS is used to synthesize metallic nanoparticle-toughened ceramics [15]. During the SPS of the $\mathrm{Al}_{2} \mathrm{O}_{3}-\mathrm{NiAl}_{2} \mathrm{O}_{4}$ twophase composite synthesized by co-precipitation and calcination, Ni nucleated from the $\mathrm{NiAl}_{2} \mathrm{O}_{4}$ phase so that in the resultant composite, $\mathrm{Ni}$ nanoparticles were uniformly distributed in the matrix of $\mathrm{Al}_{2} \mathrm{O}_{3}$. The presence of metallic nanoparticles improved the bending strength and fracture toughness of the nanocomposite relative to $\mathrm{Al}_{2} \mathrm{O}_{3}$.

Successful synthesis and consolidation of metal matrix composites containing nanoparticles of reinforcing phases by reactive SPS have been demonstrated for $\mathrm{Ti}_{5} \mathrm{Si}_{3}$ - Ti [42] and $\mathrm{Fe}_{3} \mathrm{C}$-Fe systems [43]. The distribution uniformity of $\mathrm{Si}$ achieved during mechanical milling of $\mathrm{Ti}-\mathrm{Si}$ powder mixtures ensured the formation of $100-200 \mathrm{~nm} \mathrm{Ti}_{5} \mathrm{Si}_{3}$ particles during the SPS; these particles stabilized an ultra-fine grained structure of the Ti matrix $(200-400 \mathrm{~nm})$, smaller titanium grains being observed in composites with higher $\mathrm{Si}$ 


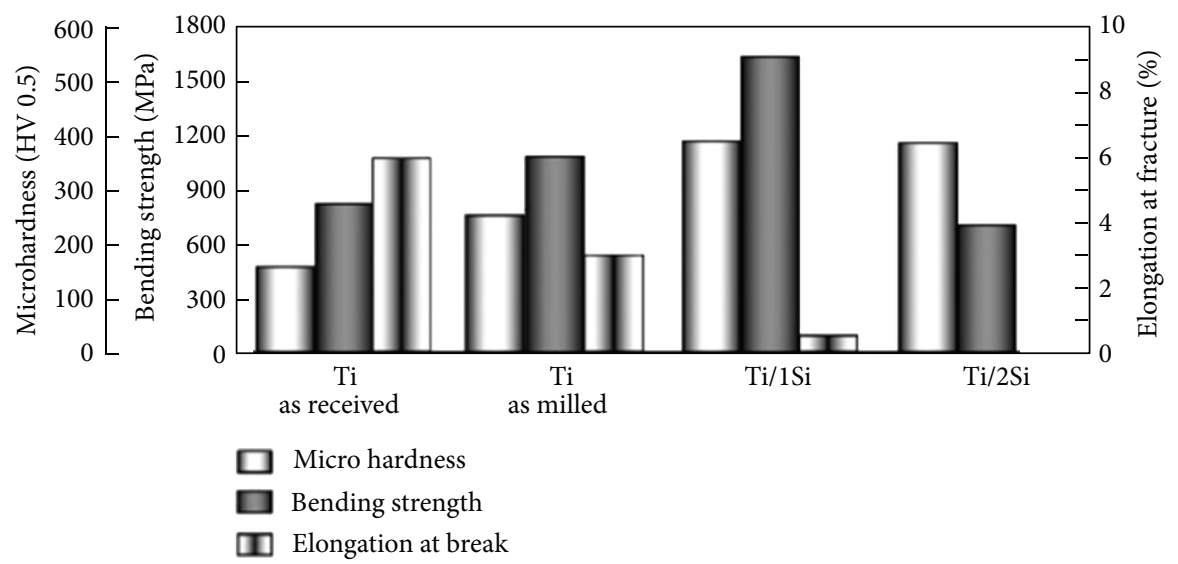

FIgure 9: Microhardness, bending strength, and elongation at fracture of SPS-ed Ti-based materials; $\mathrm{Ti} / 1 \mathrm{Si}$ and $\mathrm{Ti} / 2 \mathrm{Si}$ denote $\mathrm{Ti} \mathrm{Si}_{5}-\mathrm{Ti}$ composites containing 1 and 2 wt.\% of Si, respectively, (reprinted from [42], Copyright (2006), with permission from Elsevier).

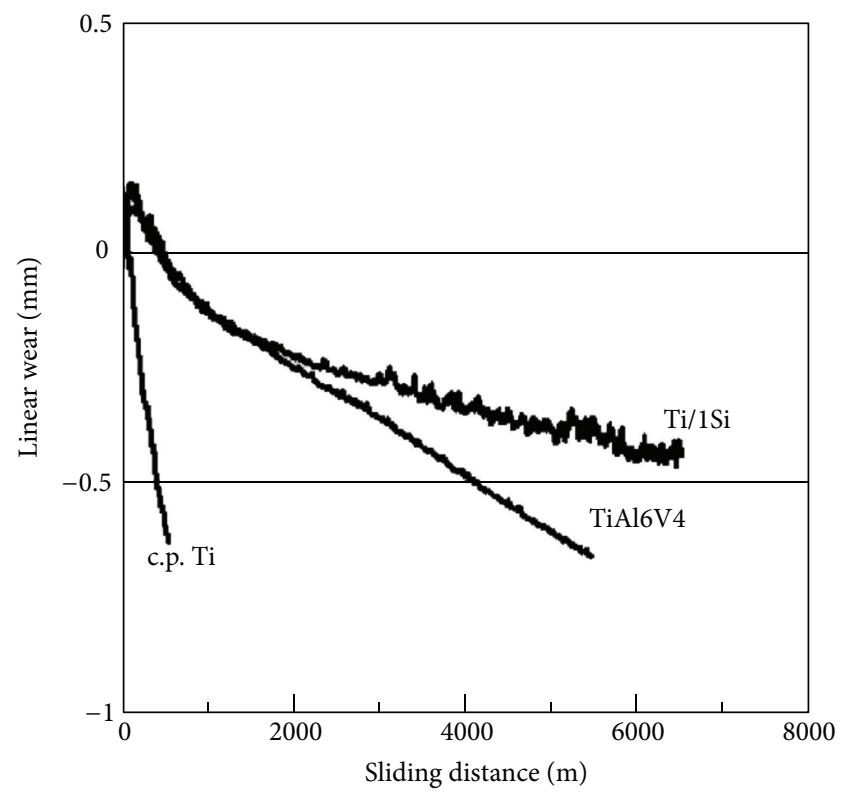

FIGURE 10: Wear behavior of $\mathrm{Ti}^{-} \mathrm{Ti}_{5} \mathrm{Si}_{3}$ composites (Si content 1 wt.\%) produced by mechanical milling and SPS compared to that of pure titanium and the TiAl6V4 alloy (reprinted from [42], Copyright (2006), with permission from Elsevier).

content [42]. This unique microstructure was responsible for attractive mechanical properties of the $\mathrm{Ti}_{5} \mathrm{Si}_{3}-\mathrm{Ti}$ composite possessing strength comparable to that of the Ti6Al4V alloy and improved wear resistance (Figures 9 and 10). Interesting combinations of strength and ductility were achieved in Fe-C alloys produced by SPS of mechanically milled mixtures of iron and graphite, the formation of cementite $\mathrm{Fe}_{3} \mathrm{C}$ taking place during sintering of a nanostructured precursor [43]. The fully dense materials were composed of a nanostructured ferrite matrix having an average grain size of $150 \mathrm{~nm}$ and cementite $\mathrm{Fe}_{3} \mathrm{C}$ dispersoids a few nanometers in size distributed in the ferrite grains and along the grain boundaries. The yield strength of the SPS-ed $\mathrm{Fe}-\mathrm{Fe}_{3} \mathrm{C}$ composite was $2000 \mathrm{MPa}$, while its fracture strength and plastic strain reached $3500 \mathrm{MPa}$ and $40 \%$, respectively. High plastic deformation of the composite was an interesting finding, as nanostructured Fe-based alloys produced by other consolidation methods are normally much more brittle. This unique behavior of the $\mathrm{Fe}-\mathrm{Fe}_{3} \mathrm{C}$ composites was attributed to its full density, good metallurgical bonding achieved during the SPS, and a uniform distribution of the dispersoid phase retaining its fine size after sintering and preventing the material failure by inhomogeneous deformation during shear events rather characteristic of other Fe-based nanocrystalline alloys.

\section{Challenges of Producing Dense Nanomaterials by Reactive SPS}

The microstructure development during the reactive SPS follows one of the two possible scenarios: (1) simultaneous reaction and densification; (2) complete reaction followed by densification (if the latter is aimed at) at higher temperatures. A chemical reaction within a narrow temperature range accompanied by shrinkage of the sample is the best situation for the formation of a dense nanostructured product [9]. However, the reaction and densification steps do not always coincide during the reactive SPS. When the reaction is complete before densification starts, then, in order to obtain a fully dense product, one has to resort to higher-temperature sintering. Anselmi-Tamburini et al. [44] have shown that boron carbide $\mathrm{B}_{4} \mathrm{C}$ forms in the mixtures of amorphous boron and carbon black at $1200^{\circ} \mathrm{C}$ during the SPS, while temperatures as high as $1900^{\circ} \mathrm{C}$ are required to produce a dense compact from the reaction product. In certain cases, full density sintered products can only be obtained when the fine structure of the material is sacrificed. The interrelation between the grain size and density of boron carbide $\mathrm{B}_{4} \mathrm{C}$ synthesized from the mixtures of amorphous boron and carbon black nanopowders was demonstrated by Hulbert et al. [45, 46], who used an off-set die in the SPS facility. Modeling of the process suggested that the difference between the temperatures of the upper and bottom parts of the sample was $400 \mathrm{~K}$. The sintered material had a gradient structure in 


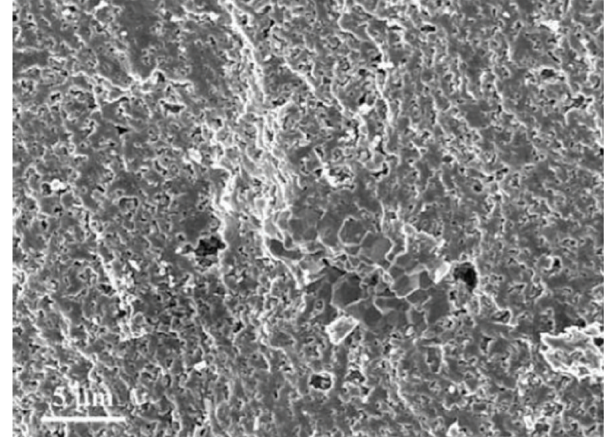

(a)

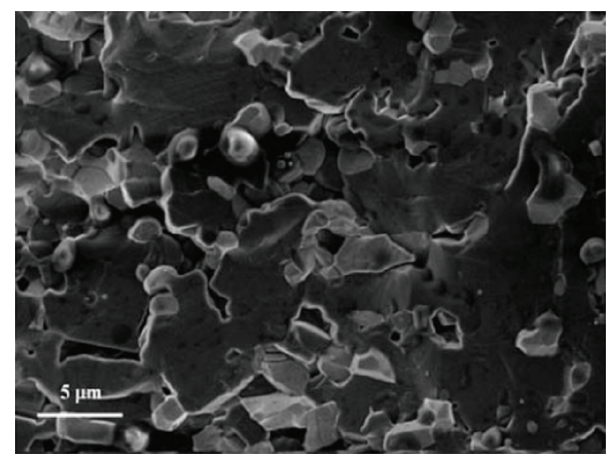

(b)

FIgURE 11: Fracture surface of the $\mathrm{TiB}_{2}-\mathrm{B}_{4} \mathrm{C}$ composite showing an agglomerate of $\mathrm{TiB}_{2}$ with a pore in the center, reactant mixture milled for $4 \mathrm{~h}$, SPS-ed at 1600 (a); a nearly fully dense $\mathrm{TiB}_{2}-\mathrm{B}_{4} \mathrm{C}$, reactant mixture milled for $16 \mathrm{~h}$, SPS-ed at 1700 (b) (reprinted from [48], Copyright (2009), with permission from Elsevier).

terms of grain size and porosity. Within the sample, a finegrained porous $\mathrm{B}_{4} \mathrm{C}$ with grains of $200 \mathrm{~nm}$ was formed in the regions subjected to lower temperatures, while dense boron carbide with grains about $2 \mu \mathrm{m}$ in size could be found in parts of the sample that experienced higher sintering temperatures.

In single-phase materials synthesized by reactive SPS, the microstructure evolution can be described using the grain size and porosity characteristics. In composite materials, the grain size may not be the same for all constituent phases depending on the mechanism of the synthesis reaction and the tendency of each material to coarsen during sintering. The porosity distribution may not be uniform throughout the volume of the composite. When working with a multiphase material, one has to take into account the differences in properties of the phases, such as characteristic grain growth and densification rates. An illustration of the above considerations is the in situ synthesized $\mathrm{B}_{4} \mathrm{C}-23$ vol. $\% \mathrm{TiB}_{2}$ composites obtained by reactive SPS from Ti-B-C mechanically milled mixtures [47, 48]. The agglomeration of titanium diboride is seen in the SPS-ed $\mathrm{B}_{4} \mathrm{C}-\mathrm{TiB}_{2}$ samples that were milled for durations insufficient for a uniform distribution of titanium [47]. The agglomerates of titanium diboride consisted of faceted grains $1-2 \mu \mathrm{m}$ in size and contained a pore in the center (Figure 11).

In the same sample, the boron carbide phase showed much smaller grains. The presence of a pore inside the $\mathrm{TiB}_{2}$ agglomerate can be explained by a decrease in the specific volume that accompanies the reaction between metallic titanium and boron. Faster densification of the synthesized boron carbide, whose content in the composite was 77 vol.\% and which thus played the role of a matrix being already quite dense by the moment the reaction between $\mathrm{Ti}$ and $\mathrm{B}$ was complete, did not allow $\mathrm{TiB}_{2}$ grains to rearrange and better sinter between themselves. Due to refractory nature of $\mathrm{TiB}_{2}$, its agglomerates comprised the major part of the total porosity of the composites. In order to eliminate this porosity, the distribution of titanium should be more uniform, which was achieved by a longer mechanical milling of the reactant mixtures. As is seen from Figure 11(b), the nearly fully dense material had micron-sized grains of both phases. Similar observation for the $\mathrm{B}_{4} \mathrm{C}-\mathrm{TiB}_{2}$ composites was reported by Nikzad et al. [49] showing that a relative density of $98 \%$ could be only achieved allowing marked grain growth to happen. The gradually coarsening microstructure of the in situ $\mathrm{B}_{4} \mathrm{C}$ $\mathrm{TiB}_{2}$ composites obtained upon increasing electric current while keeping the other experimental parameters constant is demonstrated in Figure 12. Although submicron grains can be seen in the sample SPS-ed at $1100 \mathrm{~A}$ and having a relative density of $94 \%$, the sample of $98 \%$ relative density reveals excessive grain growth such that both phases are represented by grains of several microns.

\section{Outlook}

As the information on the successes of SPS in the rapid and convenient synthesis of new materials and compounds as well as previously known materials but of improved microstructure and properties penetrates into new areas of materials science, an increasing number of researchers express their interest in performing feasibility tests and later on to embark on a systematic study of the synthesis of their materials with the help of this promising method. In the past two decades, we have seen a large number of studies on reactive SPS. Most of them are based on chemical reactions between premixed reactants to synthesize new compounds and composites. A pathway to nanostructured products through decomposition reactions well established in materials science has not yet been given full attention in regard to the SPS capabilities. Thermal decomposition of salts [50] resulting in the formation of metal nanoparticles can become reactions of choice to be performed in the SPS. In the coming years, new syntheses routes can be anticipated to be found for various materials using SPS in its usual design as well as with new geometries of dies and punches. Once the conditions for the nanostructure formation are established using simple geometries, the temperature distribution in the reacting sample can be varied by a more elaborate design of the die-punch setup. The synthesis thus can be implemented to give microstructures with gradients in the grain size and porosity including bodies of tubular geometries [51]. The successes of reactive SPS in synthesizing bulk nanostructured materials can be further extended by the simultaneous synthesis and, joining of two materials [52] as well as by the manufacturing of nanostructured coatings [53-55]. 


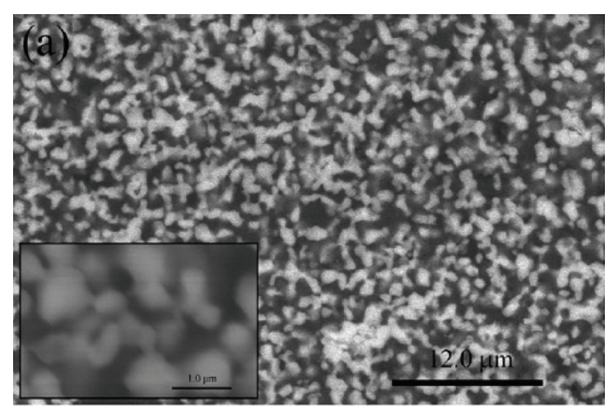

(a)

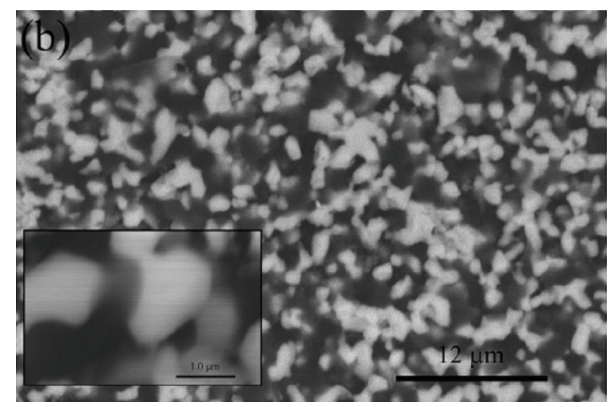

(b)

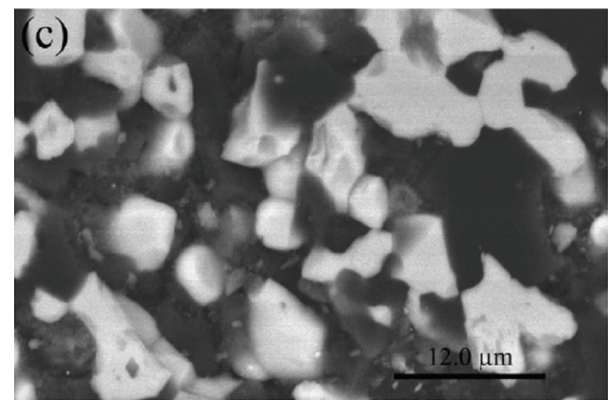

(c)

FIGURE 12: Microstructure of the $\mathrm{B}_{4} \mathrm{C}-\mathrm{TiB}_{2}$ composites SPS-ed using different electric current values ((a) - $1100 \mathrm{~A},(\mathrm{~b})-1150 \mathrm{~A}$, and (c) 1200 A) (reprinted from [49], Copyright (2012), with permission from Elsevier).

\section{Conclusions}

Initially designed for conducting solid state sintering, SPS has been proved to be attractive for conducting solid state chemical reactions. Being a powerful technique and a userfriendly facility, SPS has been developed into a method of solid state synthesis under applied electric current and mechanical pressure. An increasing number of solid state chemists consider SPS as a new tool, full capabilities of which are yet to be discovered. If the reactants are mixed at the nanolevel, then the formation of a nanograined product during the SPS will be favored. However, there exists a specific microstructure development path with multiple intermediate reaction products: even though the reaction started in the mixture of coarse-grained powders, its final products can be composed of nanograins. Making a dense material from the nanostructured reaction product in the SPS is another challenge; in certain cases, when the reaction is complete before any substantial densification occurs, successful consolidation cannot be achieved without sacrificing the as synthesized nanostructure. However, applying the same principles of optimization of the SPS parameters as those used for consolidation of ex situ produced nanopowders, a processing parameter window can be found to maintain the fine grain size of the reaction product until the sintering completion.

\section{Acknowledgments}

Professor Amiya K. Mukherjee acknowledges support by a grant from the US Office of Naval Research (ONR Grant no. N00014-10-1-0632) with Dr. Lawrence Kabacoff as the Program Manager. Dr. Dina V. Dudina acknowledges support by a grant from the Mayor's Office of Novosibirsk, Russian Federation (15-12, 24.05.2012).

\section{References}

[1] M. Tokita, "Trends in advanced SPS spark plasma sintering systems and technology," Journal of the Society of Powder Technology Japan, vol. 30, no. 11, pp. 790-804, 1993.

[2] J. R. Groza and A. Zavaliangos, "Sintering activation by external electrical field," Materials Science and Engineering A, vol. 287, no. 2, pp. 171-177, 2000.

[3] U. Anselmi-Tamburini, S. Gennari, J. E. Garay, and Z. A. Munir, "Fundamental investigations on the spark plasma sintering/synthesis process: II. Modeling of current and temperature distributions," Materials Science and Engineering A, vol. 394, no. 1-2, pp. 139-148, 2005.

[4] U. Anselmi-Tamburini, J. E. Garay, and Z. A. Munir, "Fundamental investigations on the spark plasma sintering/synthesis process. III. Current effect on reactivity," Materials Science and Engineering A, vol. 407, no. 1-2, pp. 24-30, 2005.

[5] Z. A. Munir, U. Anselmi-Tamburini, and M. Ohyanagi, "The effect of electric field and pressure on the synthesis and consolidation of materials: a review of the spark plasma sintering method," Journal of Materials Science, vol. 41, no. 3, pp. 763-777, 2006.

[6] Z. A. Munir, D. V. Quach, and M. Ohyanagi, "Electric current activation of sintering: a review of the pulsed electric current sintering process," Journal of the American Ceramic Society, vol. 94, no. 1, pp. 1-19, 2011.

[7] D. M. Hulbert, A. Anders, D. V. Dudina et al., "The absence of plasma in 'spark plasma sintering," Journal of Applied Physics, vol. 104, no. 3, Article ID 033305, 2008.

[8] T. Holland, T. B. Tran, D. V. Quach, U. Anselmi-Tamburini, J. R. Groza, and A. K. Mukherjee, "Athermal and thermal mechanisms of sintering at high heating rates in the presence and absence of an externally applied field," Journal of the European Ceramic Society, vol. 32, no. 14, pp. 3675-3683, 2012.

[9] Z. A. Munir, "Synthesis and densification of nanomaterials by mechanical and field activation," Journal of Materials Synthesis and Processing, vol. 8, no. 3-4, pp. 189-196, 2000.

[10] J. R. Groza and A. Zavaliangos, "Nanostructured bulk solids by field activated sintering," Reviews on Advanced Materials Science, vol. 5, no. 1, pp. 24-33, 2003.

[11] N. Saheb, Z. Iqbal, A. Khalil et al., "Spark Plasma Sintering of metals and metal matrix nanocomposites: a review," Journal of Nanomaterials, vol. 2012, Article ID 983470, 13 pages, 2012. 
[12] R. Orrù, R. Licheri, A. M. Locci, A. Cincotti, and G. Cao, "Consolidation/synthesis of materials by electric current activated/assisted sintering," Materials Science and Engineering R, vol. 63, no. 4-6, pp. 127-287, 2009.

[13] T. Hungría, J. Galy, and A. Castro, "Spark plasma sintering as a useful technique to the nanostructuration of piezo-ferroelectric materials," Advanced Engineering Materials, vol. 11, no. 8, pp. 615-631, 2009.

[14] T. Isobe, K. Daimon, K. Ito, T. Matsubara, Y. Hikichi, and T. Ota, "Preparation and properties of $\mathrm{Al}_{2} \mathrm{O}_{3} / \mathrm{Ni}$ composite from $\mathrm{NiAl}_{2} \mathrm{O}_{4}$ spinel by in situ reaction sintering method," Ceramics International, vol. 33, no. 7, pp. 1211-1215, 2007.

[15] T. Isobe, K. Daimon, T. Sato, T. Matsubara, Y. Hikichi, and T. Ota, "Spark plasma sintering technique for reaction sintering of $\mathrm{Al}_{2} \mathrm{O}_{3} / \mathrm{Ni}$ nanocomposite and its mechanical properties," Ceramics International, vol. 34, no. 1, pp. 213-217, 2008.

[16] C.-B. Rong, V. Nandwana, N. Poudyal et al., "Bulk FePt Fe ${ }_{3} \mathrm{Pt}$ nanocomposite magnets prepared by spark plasma sintering," Journal of Applied Physics, vol. 101, no. 9, Article ID 09K515, 2007.

[17] J. Gurt Santanach, C. Estournès, A. Weibel, A. Peigney, G. Chevallier, and C. Laurent, "Spark plasma sintering as a reactive sintering tool for the preparation of surface-tailored Fe$\mathrm{FeAl}_{2} \mathrm{O}_{4}-\mathrm{Al}_{2} \mathrm{O}_{3}$ nanocomposites," Scripta Materialia, vol. 60, no. 4, pp. 195-198, 2009.

[18] D. Salamon, M. Eriksson, M. Nygren, and Z. Shen, "Homogeneous $\mathrm{TiB}_{2}$ ceramics achieved by electric current-assisted self-propagating reaction sintering," Journal of the American Ceramic Society, vol. 90, no. 10, pp. 3303-3306, 2007.

[19] A. M. Locci, R. Licheri, R. Orrù, and G. Cao, "Reactive Spark Plasma Sintering of rhenium diboride," Ceramics International, vol. 35, no. 1, pp. 397-400, 2009.

[20] U. Anselmi-Tamburini, Y. Kodera, M. Gasch et al., "Synthesis and characterization of dense ultra-high temperature thermal protection materials produced by field activation through spark plasma sintering (SPS): I. Hafnium diboride," Journal of Materials Science, vol. 41, no. 10, pp. 3097-3104, 2006.

[21] J. Schmidt, R. Niewa, M. Schmidt, and Y. Grin, "Spark plasma sintering effect on the decomposition of $\mathrm{MgH}_{2}$," Journal of the American Ceramic Society, vol. 88, no. 7, pp. 1870-1874, 2005.

[22] D. Jiang and A. K. Mukherjee, "The influence of oxygen vacancy on the optical transmission of an yttria-magnesia nanocomposite," Scripta Materialia, vol. 64, no. 12, pp. 1095-1097, 2011.

[23] J. H. Noh, H. S. Jung, I.-S. Cho et al., "Enhancing the densification of nanocrystalline $\mathrm{TiO}_{2}$ by reduction in spark plasma sintering," Journal of the American Ceramic Society, vol. 93, no. 4, pp. 993-997, 2010.

[24] D. J. Roberts, J. Zhao, and Z. A. Munir, "Mechanism of reactive sintering of MgAlB14 by pulse electric current," International Journal of Refractory Metals and Hard Materials, vol. 27, no. 3, pp. 556-563, 2009.

[25] D. V. Dudina, V. I. Mali, A. G. Anisimov et al., " $\mathrm{Ti}_{3} \mathrm{SiC}_{2}-\mathrm{Cu}$ composites by mechanical milling and Spark Plasma Sintering: possible microstructure formation scenarios," Metals and Materials International. In press.

[26] D. Jiang, D. M. Hulbert, U. Anselmi-Tamburini, T. Ng, D. Land, and A. K. Mukherjee, "Optically transparent polycrystalline $\mathrm{Al}_{2} \mathrm{O}_{3}$ produced by spark plasma sintering," Journal of the American Ceramic Society, vol. 91, no. 1, pp. 151-154, 2008.

[27] J. S. Kim, H. S. Choi, D. Dudina, J. K. Lee, and Y. S. Kwon, "Spark plasma sintering of nanoscale $(\mathrm{Ni}+\mathrm{Al})$ powder mixture," Diffusion and Defect Data B, vol. 119, pp. 35-38, 2007.
[28] H. Wang, S.-H. Lee, and H.-D. Kim, "Nano-hafnium diboride powders synthesized using a spark plasma sintering apparatus," Journal of the American Ceramic Society, vol. 95, no. 5, pp. 14931496, 2012.

[29] L. Stanciu, J. R. Groza, L. Stoica, and C. Plapcianu, "Influence of powder precursors on reaction sintering of $\mathrm{Al}_{2} \mathrm{TiO}_{5}$," Scripta Materialia, vol. 50, no. 9, pp. 1259-1262, 2004.

[30] J. Zhang, L. Wang, L. Shi, W. Jiang, and L. Chen, "Rapid fabrication of $\mathrm{Ti}_{3} \mathrm{SiC}_{2}-\mathrm{SiC}$ nanocomposite using the spark plasma sintering-reactive synthesis (SPS-RS) method," Scripta Materialia, vol. 56, no. 3, pp. 241-244, 2007.

[31] R.-G. Duan, J. D. Kuntz, J. E. Garay, and A. K. Mukherjee, "Metal-like electrical conductivity in ceramic nano-composite," Scripta Materialia, vol. 50, no. 10, pp. 1309-1313, 2004.

[32] C. Suryanarayana, "Mechanical alloying and milling," Progress in Materials Science, vol. 46, no. 1-2, pp. 1-184, 2001.

[33] L. Wang, T. Wu, W. Jiang, J. Li, and L. Chen, "Novel fabrication route to $\mathrm{Al}_{2} \mathrm{O}_{3}$-TiN nanocomposites via spark plasma sintering," Journal of the American Ceramic Society, vol. 89, no. 5, pp. 1540-1543, 2006.

[34] S. Ishihara, W. Zhang, H. Kimura, M. Omori, and A. Inoue, "Consolidation of Fe-Co-Nd-Dy-B glassy powders by sparkplasma sintering and magnetic properties of the consolidated alloys," Materials Transactions, vol. 44, no. 1, pp. 138-143, 2003.

[35] L. Perrière, M. T. Thai, S. Tusseau-Nenez, M. Blétry, and Y. Champion, "Spark plasma sintering of a Zr-based metallic glass," Advanced Engineering Materials, vol. 13, no. 7, pp. 581586, 2011.

[36] J. Wan, R.-G. Duan, M. J. Gasch, and A. K. Mukherjee, "Methods of processing $\mathrm{Si}_{3} \mathrm{~N}_{4} / \mathrm{SiC}$ nano-nano composites from polymer precursor," Materials Science and Engineering A, vol. 424, no. 1-2, pp. 105-116, 2006.

[37] R.-G. Duan, J. E. Garay, J. D. Kuntz, and A. K. Mukherjee, "Electrically conductive in situ formed nano- $\mathrm{Si}_{3} \mathrm{~N}_{4} / \mathrm{SiC} / \mathrm{TiC}_{x} \mathrm{~N}_{1-x}$ ceramic composite consolidated by Pulse Electric Current Sintering (PECS)," Journal of the American Ceramic Society, vol. 88, no. 1, pp. 66-70, 2005.

[38] S. Paris, E. Gaffet, F. Bernard, and Z. A. Munir, "Spark plasma synthesis from mechanically activated powders: a versatile route for producing dense nanostructured iron aluminides," Scripta Materialia, vol. 50, no. 5, pp. 691-696, 2004.

[39] Z. Zhang, X. Shen, F. Wang, and S. Lee, "A new rapid route for in situ synthesizing monolithic TiB ceramic," Journal of the American Ceramic Society, vol. 94, no. 9, pp. 2754-2756, 2011.

[40] J. W. Lee, Z. A. Munir, M. Shibuya, and M. Ohyanagi, "Synthesis of dense $\mathrm{TiB}_{2}$-TiN nanocrystalline composites through mechanical and field activation," Journal of the American Ceramic Society, vol. 84, no. 6, pp. 1209-1216, 2001.

[41] G. Cabouro, S. Chevalier, E. Gaffet, Y. Grin, and F. Bernard, "Reactive sintering of molybdenum disilicide by spark plasma sintering from mechanically activated powder mixtures: processing parameters and properties," Journal of Alloys and Compounds, vol. 465, no. 1-2, pp. 344-355, 2008.

[42] D. Handtrack, F. Despang, C. Sauer, B. Kieback, N. Reinfried, and Y. Grin, "Fabrication of ultra-fine grained and dispersionstrengthened titanium materials by spark plasma sintering," Materials Science and Engineering A, vol. 437, no. 2, pp. 423-429, 2006.

[43] H. W. Zhang, R. Gopalan, T. Mukai, and K. Hono, "Fabrication of bulk nanocrystalline Fe-C alloy by spark plasma sintering of mechanically milled powder," Scripta Materialia, vol. 53, no. 7, pp. 863-868, 2005. 
[44] U. Anselmi-Tamburini, Z. A. Munir, Y. Kodera, T. Imai, and M. Ohyanagi, "Influence of synthesis temperature on the defect structure of boron carbide: experimental and modeling studies," Journal of the American Ceramic Society, vol. 88, no. 6, pp. 13821387, 2005.

[45] D. M. Hulbert, D. Jiang, U. Anselmi-Tamburini, C. Unuvar, and A. K. Mukherjee, "Experiments and modeling of spark plasma sintered, functionally graded boron carbide-aluminum composites," Materials Science and Engineering A, vol. 488, no. 1-2, pp. 333-338, 2008.

[46] D. M. Hulbert, D. Jiang, U. Anselmi-Tamburini, C. Unuvar, and A. K. Mukherjee, "Continuous functionally graded boron carbide-aluminum nanocomposites by spark plasma sintering," Materials Science and Engineering A, vol. 493, no. 1-2, pp. 251255, 2008.

[47] D. V. Dudina, D. M. Hulbert, D. Jiang, C. Unuvar, S. J. Cytron, and A. K. Mukherjee, "In situ boron carbide-titanium diboride composites prepared by mechanical milling and subsequent Spark Plasma Sintering," Journal of Materials Science, vol. 43, no. 10, pp. 3569-3576, 2008.

[48] D. M. Hulbert, D. Jiang, D. V. Dudina, and A. K. Mukherjee, "The synthesis and consolidation of hard materials by spark plasma sintering," International Journal of Refractory Metals and Hard Materials, vol. 27, no. 2, pp. 367-375, 2009.

[49] L. Nikzad, R. Licheri, T. Ebadzadeh, R. Orrù, and G. Cao, "Effect of ball milling on reactive spark plasma sintering of $\mathrm{B}_{4} \mathrm{C}-\mathrm{TiB}_{2}$," Ceramics International, vol. 38, no. 8, pp. 6469-6480, 2012.

[50] B. B. Bokhonov, L. P. Burleva, D. R. Whitcomb, and Y. E. Usanov, "Formation of nano-sized silver particles during thermal and photochemical decomposition of silver carboxylates," Journal of Imaging Science and Technology, vol. 45, no. 3, pp. 259-266, 2001.

[51] T. Holland, D. Hulbert, U. Anselmi-Tamburini, and A. Mukherjee, "Functionally graded boron carbide and aluminum composites with tubular geometries using pulsed electric current sintering," Materials Science and Engineering A, vol. 527, no. 1819, pp. 4543-4545, 2010.

[52] W. Liu and M. Naka, "In situ joining of dissimilar nanocrystalline materials by spark plasma sintering," Scripta Materialia, vol. 48, no. 9, pp. 1225-1230, 2003.

[53] T. Matsubara, T. Shibutani, K. Uenishi, and K. F. Kobayashi, "Fabrication of $\mathrm{TiB}_{2}$ reinforced $\mathrm{Al}_{3} \mathrm{Ti}$ composite layer on Ti substrate by reactive-pulsed electric current sintering," Materials Science and Engineering A, vol. 329-331, pp. 84-91, 2002.

[54] M. Mulukutla, A. Singh, and S. P. Harimkar, "Spark plasma sintering for multi-scale surface engineering of materials," Journal of Metals, vol. 62, no. 6, pp. 65-71, 2010.

[55] A. Singh, S. R. Bakshi, D. A. Virzi, A. K. Keshri, A. Agarwal, and S. P. Harimkar, "In-situ synthesis of $\mathrm{TiC} / \mathrm{SiC} / \mathrm{Ti}_{3} \mathrm{SiC}_{2}$ composite coatings by spark plasma sintering," Surface and Coatings Technology, vol. 205, no. 13-14, pp. 3840-3846, 2011. 

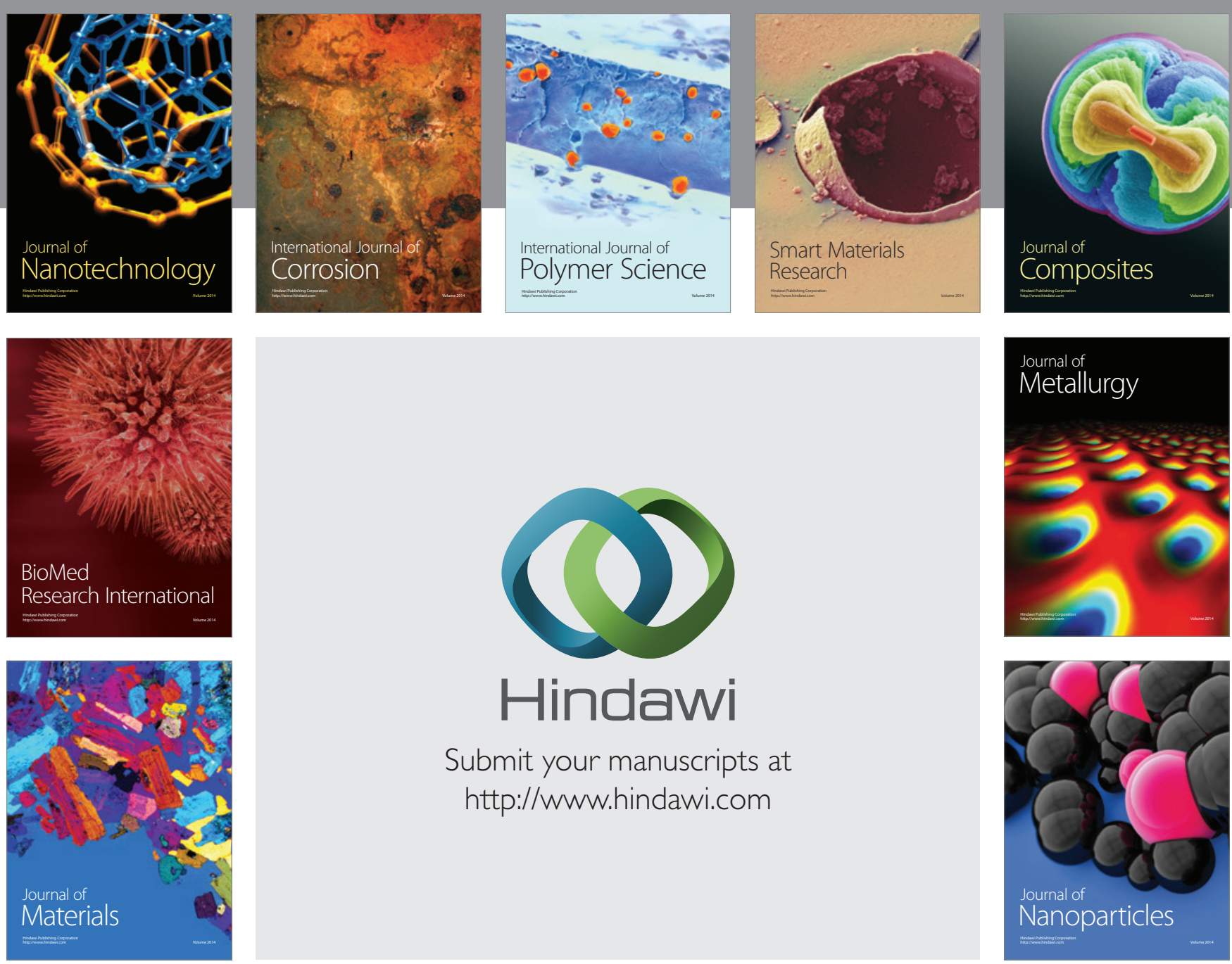

Submit your manuscripts at http://www.hindawi.com
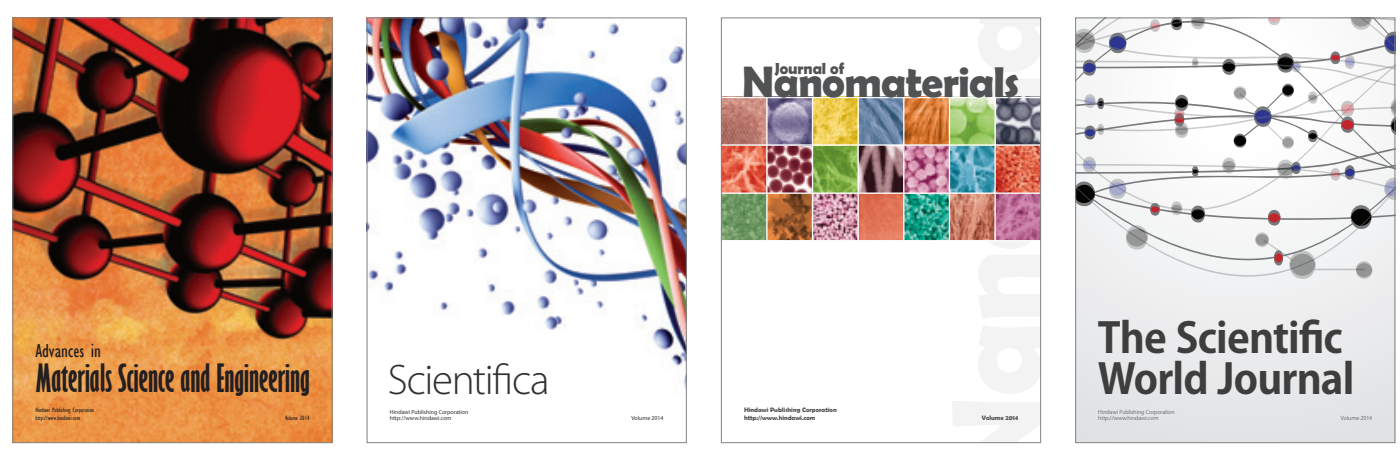

\section{The Scientific World Journal}
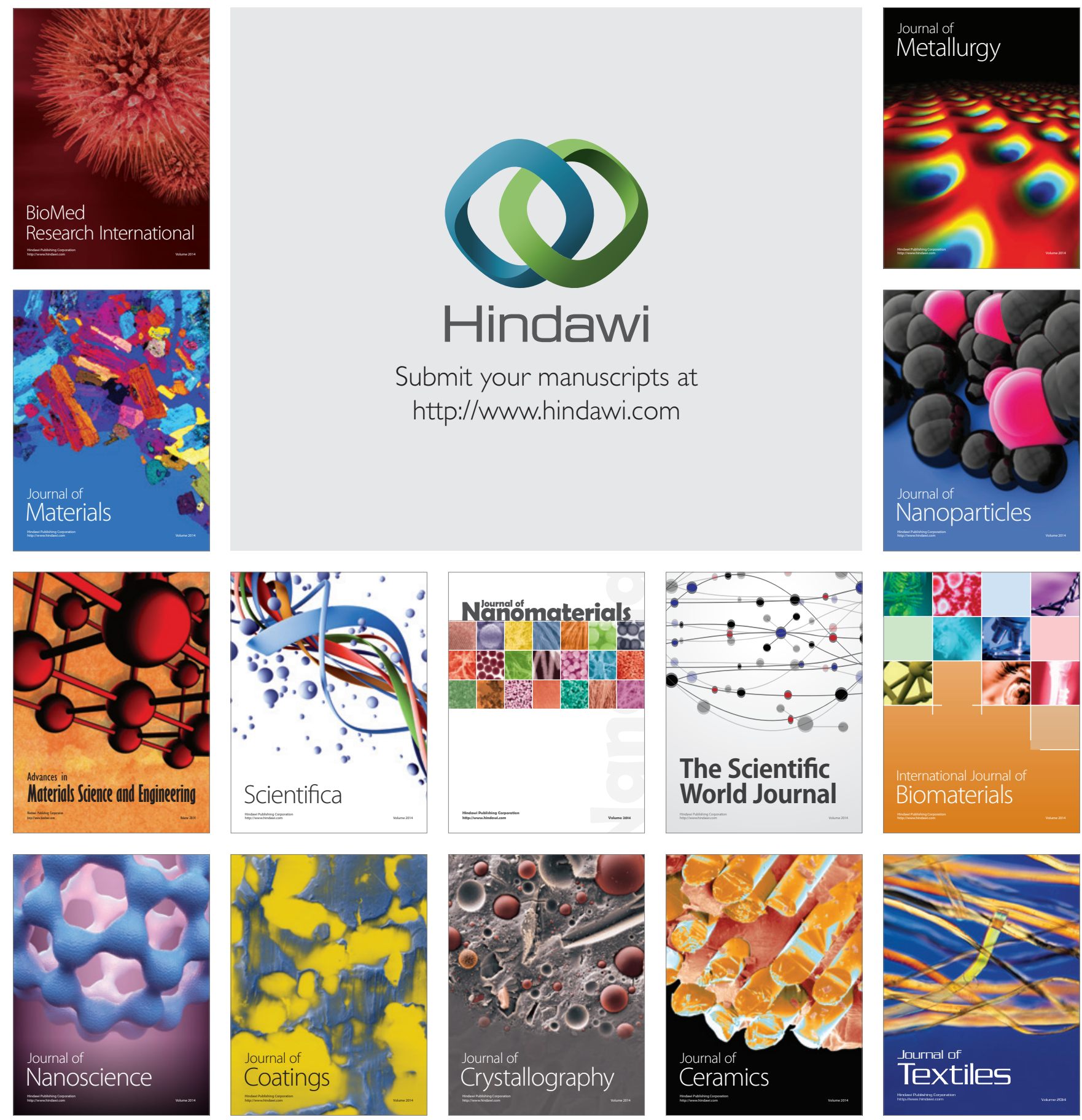